to promote the welfare of themselves and of their children, great expenses must be incurred, but if we are to be a Department of Preventive Medicine in the true sense of the word, we must face these expenses, and face them in the most far-seeing manner possible.

\title{
Public Opinion and the Unmarried Mother.
}

By Miss H. M. Welis. Welfare Supervisor, National Ordnance Factory, Nottingham.

\section{(ABSTRACT).}

THE object of this paper is to show that our harsh laws and unkind treatment of the unmarried mother having done nothing towards solving the problem of illegitimacy, and tending only to drive our young people to a further sin, it becomes more and more urgent to think out and decide upon definite plans of action, whereby mother and child may be given the means to work out each other's salvation. Public opinion has changed during the last few years and is assuming a much kinder, more understanding attitude. To-day it is recognised that the mere fact. of having an illegitimate child should not brand a girl as immoral. More likely she has been guilty of a temporary immorality, whereas the immoral girl manages to escape open disgrace by avoiding maternal responsibility.

There are several different types of unmarried mothers, and the problem assumes a different aspect according to the nature, character, and disposition of the girl.

It is the destruction of the family unit which should be recognised as a crime against nature.

To deal with the problem satisfactorily, mother and babe must be kept together. Hostels with day nurseries attached are being established where mothers can live with their children for at least a year. The mothers go out to work during the day, returning in the evening to resume responsibility. These hostels, by protecting the mother and sharing the responsibility and support of the child, help to supply the paternal factor which is lacking. The life and health of the babe depends on its intimate relationship with the mother; it is through the influence of her child that the mother regains her self-respect and may be restored to good citizenship.

\section{Some Observations on the Illegitimate Child.}

By J. Thomson Dick, M.B., D.P.H., Assist. M.O.H., County of Lanark.

THE average number of illegitimate children born each year in Scotland,

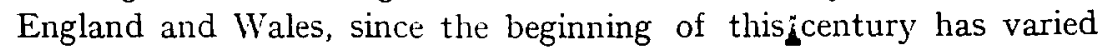
very little and amounts to about 45,000 . Taking the countries separately 